\title{
UMA HISTÓRIA DENTRO DA HISTÓRIA. MACAÍBA: ECONOMIAS TRADICIONAIS E MODERNAS NA (RE) PRODUÇÃO DO ESPAÇO
}

\author{
K. F. Santos' e A. A. Costa ${ }^{2}$ \\ ${ }^{1}$ Instituto Federal do Rio Grande do Norte e ${ }^{2}$ Universidade Federal do Rio Grande do Norte \\ 1kathiusciafernandes@hotmail.come 2ademir@ufrnet.br
}

Artigo submetido em outubro/2011 e aceito em março/2012

\section{RESUMO}

A ideia de produção está pressuposta a ideia de espaço. Pois, não há produção sem um espaço e não há um espaço sem produção. Assim, as instâncias sociais, econômica e espacial são interligadas. Baseando-se neste pensamento este trabalho objetiva analisar a formação espacial de Macaíba a partir das economias tradicionais e as mudanças ocasionadas pelas novas economias instaladas no município. Para tanto, busca-se realiza uma analogia entre o processo de formação do Rio Grande do Norte e o de Macaíba, por esta de constituir em um subespaço do Estado. Para alcançar tal objetivo utilizou-se de pesquisas bibliográficas e registros fotográficos. Dessa forma, pode-se perceber como as atividades tradicionais à medida que se instalavam produziam o território adequado a suas necessidades e após a crise das economias tradicionais, analisamos como as economias modernas foram reproduzindo esse território.

PALAVRAS-CHAVE: Economias, Território, Macaíba.

\section{A STORY IN HISTORY. MACAÍBA: ECONOMIES IN TRADITIONAL AND MODERN (RE) PRODUCTION OF SPACE}

\begin{abstract}
The idea of production is presupposed the idea of place. Well, there is no production without a space is there an area without production. Thus, social levels: economic and space are intertwined. Based on this thinking this paper analyzed the spatial formation of Macaíba from traditional economies and the changes caused by new economies located in the municipality. To accomplish this we used the literature searches and photographic records. In which, yet we
\end{abstract}

tried to make an analogy between the process of formation of the Rio Grande do Norte and the Macaiba for this to be a subspace in the state. Thus, one cansee how traditional activities as producing the territory settled suits their needs and after the crisis of traditional economies, we analyze how modern economies have been playing thisterritor.

KEY-WORDS: Economic, territorial, Macaíba. 


\section{UMA HISTÓRIA DENTRO DA HISTÓRIA. MACAÍBA: ECONOMIAS TRADICIONAIS E MODERNAS NA (RE) PRODUÇÃO DO ESPAÇO}

\section{INTRODUÇÃO}

As atividades de produção dependem de um espaço porque "[...] só a produção propriamente dita tem relação direta com o lugar e dele adquire uma parcela das condições de sua realização." (SANTOS, 2008a, p. 13). Assim, foi o processo de formação do território do Rio Grande do Norte que esteve estritamente relacionada com as atividades econômicas de produção que no território foram se instalando e dele adquirindo as condições necessárias a sua realização. Mas, como os processos acontecem em cada lugar de formas diferentes em Macaíba esses processos tomaram outra direção.

Diante disso, o presente trabalho tem como objetivo analisar a formação espacial de Macaíba a partir da economia tradicional e as mudanças ocasionadas pelas novas economias instaladas no município. Este localiza-se a $14 \mathrm{~km}$ da capital do Rio Grande do Norte, Natal. Assim, está na mesorregião leste potiguar que é constituída por 25 (vinte e cinco) municípios dos quais 09 (nove), que juntamente com Macaíba, formam a região metropolitana de Natal. Galvão (2005) ressalta que é nela que estão o suporte da rede urbana do Estado do Rio Grande do Norte e a gestão do território, já que é nesse local que estão concentradas as sedes das maiores empresas, contribuindo, assim, para o maior fluxo de pessoas, serviços, informações e bens do Estado.

A cidade tem aproximadamente 70.000 habitantes e uma área bastante expressiva, o equivalente a mais de $500 \mathrm{~km}^{2}$. Apresenta as seguintes características fisiográficas: Clima tropical chuvoso; por ser uma área de transição entre o litoral e o interior apresenta vegetação do tipo Mata Atlântica, sub-caducifólia, Caatinga e Manguezal; o relevo é de baixas elevações estando inserido nos Tabuleiros Costeiros; e Hidrografia situada na bacia do Rio Jundiaí e Pirangi. (IBGE, 2010). Entretanto, para a realização desta análise foi preciso entender como as economias formaram o território norte-rio-grandense, já que Macaíba é um subespaço ${ }^{1}$ deste.

A temática foi escolhida durante as aulas da disciplina Dinâmicas Territoriais do Rio Grande do Norte do Mestrado em Geografia da Universidade Federal do Rio Grande do Norte que proporcionou a reflexão a cerca das diversas atividades econômicas realizadas no Rio Grande do Norte e como se refletem no território produzindo e reproduzindo os espaços. Assim, pode-se perceber, ao longo das discussões, realizando associações, o quanto Macaíba foi resultado dessas transformações econômicas e, portanto, espaciais. Tornando-a uma história dentro da história.

Para a realização desse estudo foi necessária pesquisas bibliográficas e observação em locus, para realizar os registros fotográficos. Estando o trabalho estruturado da seguinte maneira. Em sua primeira seção faremos uma breve explanação sobre as instâncias sociais cujo entendimento é essencial para alcançar o objetivo do trabalho, que são: a estância econômica e espacial. Após falaremos de como as economias tradicionais foram

\footnotetext{
${ }^{1}$ Conforme Santos (2008) os diversos elementos do espaço relacionam-se uns com os outros. Relações marcadas por suas qualidades e seus atributos que formam um verdadeiro sistema. Este é comandado pelo modo de produção dominante, mas pode-se falar em regras próprias ao modo de produção em sua adaptação ao meio local gerando assim, subespaços.
}

HOLOS, Ano 28, Vol 1 
proporcionando a formação territorial do Rio Grande do Norte e atrelado a este o de Macaíba. Em seguida, trataremos das transformações espaciais ocasionadas pelas novas economias em ambas as seções ao mesmo tempo em que desvendamos como as atividades de produção, tanto as tradicionais quanto as modernas formavam o território Potiguar mostraremos seus desdobramentos no subespaço macaíbense e, por fim, serão realizadas algumas considerações.

\section{AS INSTÂNCIAS: ECONÔMICA E ESPACIAL}

Para Santos (2008b, p. 81), "O espaço sempre foi o locus da produção". Dessa forma, na própria ideia de produção está pressuposta a ideia de lugar. Com isso, tem-se uma importante integração entre as instâncias sociais, econômica e espacial, dada à necessidade de uma a outra. Pois, não há produção sem um espaço é não há um espaço sem que haja produção.

Ao longo dos períodos históricos diversos foram os modos de produção e, por tanto, de utilização do espaço e, também, quantos espaços não foram formados e/ou expandidos para suprir a necessidade da produção. Mostrando assim, o quanto são interligados. Por isso, que um esforço para uma periodização é valido uma vez que: "O sistema de periodização tem o propósito de sugerir como explicações geográficas podem ser alcançadas através de um enfoque espaciotemporal" (SANTOS, 2008b, p. 39).

Compartilhando de tal pensamento, explanar-se-á, de forma resumida, a periodização realizada pelo autor em tela, para o qual haveriam 5 (cinco) períodos: o período do comércio, em grandes escalas; o período manufatureiro; o período da revolução industrial; período industrial e o período tecnológico. Esses períodos são marcados por diversas formas de utilização do espaço. Além disso, têm como função primordial contribuir para "[...] o entendimento de como os eventos mundiais contribuem mais, para a compreensão dos subespaços, que os fenômenos locais. Este último não passando de um resultado, direto ou indireto, de forças cuja gestação ocorre à distância." (SANTOS, 2008b, p. 36).

Para o referido autor, o primeiro período coincide com o desenvolvimento do comércio e dos transportes que substituem a agricultura como fator essencial do sistema. Várias cidades europeias enriqueceram por causa do comércio o que impulsionou o surgimento o segundo período, a manufatura, que teve como principal palco o mar báltico. O terceiro tem como particularidade a industrialização, marcado com o aumento da produtividade nas áreas agrícolas, mesmo que a produção fosse apenas para o consumo interno. O quarto período corresponde à aplicação de novas tecnologias e novas formas de organização, não só da produção, mas também quanto á energia e ao transporte.

Por último tem-se o quinto período, o tecnológico. Este é, para Santos (2008b), o período das grandes indústrias e do capitalismo das corporações que se servem dos meios de comunicação extremamente difundidos e rápidos, mesmo que nem todos os espaços sejam alcançados por todas as modernizações, elas se fazem presentes mesmo que sejam de idades diferentes. Nos diferentes períodos as modernizações sempre foram impostas do centro para a periferia. Os países que recebem essas modernizações estão atendendo as necessidades de crescimento ou de funcionamento do sistema do centro. Cada período representa possibilidades para aqueles países que podem adotá-las. 
Com a periodização, é possível compreender a evolução de um subespaço quanto a sua formação social e econômica. Estas, como Libriola apud Santos (2008a) expõe, não poderão ser entendidas se não observando o movimento totalizador cujos elementos são variáveis que interagem e evoluem juntas, submetidas à lei da totalidade. É por isso, que para este autor o conceito de formação socioeconômica acaba por ser o mais adequado ao estudo da sociedade e do espaço.

Desse modo, entender os períodos históricos, em sua escala maior, é necessário para compreender como os processos aconteceram no lugar. Assim, pode-se inferir que para realizar uma análise a respeito da formação socioeconômica e, portanto, espacial de um lugar é essencial abarcar a evolução e o contexto a que se deu a produção e a utilização do espaço pelas diversas atividades econômicas que nele se instalaram. Por isso, se fará uma análise sobre a formação espacial de Macaíba a partir das economias tradicionais e as mudanças ocasionadas pelas novas economias ao município.

\section{AS ECONOMIAS TRADICIONAIS E A PRODUÇÃO DO ESPAÇO POTIGUAR}

Diversos estudos são realizados sobre a economia do Rio Grande do Norte. Mas, poucos se apropriam de uma análise espacial sobre as atividades econômicas e de como elas contribuíram para formação do território, essencial a produção, pois, de acordo com Santos (2008b, p. 81), “o processo direto de produção é tributário de um pedaço do território, adredemente organizado por uma fração da sociedade [...]".

Assim, como se deram em todo o país, as economias tradicionais foram primordiais para a apropriação e construção do território Potiguar. Variados foram os ciclos econômicos pelos quais o país passou cada um com uma organização e contribuição distinta para a formação territorial. Tratando-se das economias tradicionais, no Rio Grande do Norte especificamente três foram de grande importância para a sua organização territorial. Conforme Gomes (1998, p. 21) "Cada elemento dessa trilogia tem, no nosso entendimento, um significado específico na construção do território. A cana-de-açúcar - o ponto de partida; a pecuária - o elemento de expansão; e o algodão um produto de redefinição".

Sendo importante relembrar que os períodos são essenciais para entender como os processos de produção mundial são organizados nos subespaços. Observamos que o segundo período histórico marca o começo do processo de formação território norte-rio-grandense. Como ressalta Gomes (1998, p. 21):

Nesse contexto, o Brasil, e particularmente o Rio Grande do Norte, enquanto espaço periférico do capital, passou a complementar a produção mercantil através da produção de alimentos e matérias-primas em maiores quantidades e, portanto, a preços baixos, favorecendo, dessa forma, a valorização do capital.

Sendo assim, passaremos, mesmo que resumidamente, a entender como essas três atividades econômicas se organizaram e colaboraram para a construção do território potiguar. A primeira delas, a cana-de-açúcar, foi implantada no século XVII, logo após o sistema de 
capitanias hereditárias, adotado com o intuito de colonizar o país, o sistema não deu certo, apesar de algumas das capitanias terem prosperado.

De acordo com Gomes (1998) ao longo da história as atividades agrícolas foram as que mais contribuíram para a fixação do homem a um espaço. Assim, no Rio Grande do Norte essa foi à atividade que iniciou esse processo de ocupação territorial, mesmo que de forma pontual. Haja vista, sua concentração na faixa litorânea.

A segunda atividade foi à pecuária que contribuiu para a expansão do território para as regiões do agreste e sertão do Estado. Isto ocorreu, pois como exposto por Felipe (2010) a concentração de pessoas envolta do engenho demandava por uma produção maior de alimentos, principalmente de carne. $O$ rebanho de gado, que servia tanto para alimentação quanto como força motriz dos engenhos, não tinha a possibilidade de se desenvolver na mesma área ocupada pela atividade canavieira o que levou ao deslocamento do gado para o interior do Estado.

Por suas características devastadoras, bem como os altos custos na construção de áreas cercadas e as próprias condições naturais, não havia possibilidade das atividades da pecuária e do cultivo da cana-de-açúcar ocuparem espaços comuns (GOMES, 1998, p. 26).

A partir dessa atividade tem-se um novo arranjo espacial que passa a se beneficiar de um território mais integrado que proporcionou novas relações econômicas, novas formas de uso e a ampliação do território, onde muitas cidades tiveram o seu surgimento atrelado à atividade. (GOMES 1998).

A terceira atividade, o algodão, proporcionou uma redefinição e maior articulação no território. No contexto mundial, destaca-se o período da revolução industrial cujo algodão constituía-se matéria prima para as indústrias têxteis do período. Gomes (1998) enfatiza que os processos de redefinição do território e de articulação desencadeados foram extremamente importantes para a comercialização do produto. Além de desencadear o processo urbano proporcionando também o surgimento de cidades, para suprir a necessidade de mercados para a comercialização do produto, entre elas Macaíba.

Dessa forma, pode-se destacar a importância dessas atividades econômicas para a produção do território e como cada uma contribuiu especificamente, organizando o território as suas necessidades. Pois, este "[...] tem de ser adequado ao uso procurado e a produtividade do processo produtivo dependente, em grande parte, dessa adequação." (SANTOS, 2008b, p. 82). Entretanto, essas atividades, assim, como tiveram seu período de auge também entraram em decadência. Sendo, importante compreender as contribuições de cada uma para a formação do território.

\subsection{MACAÍBA: A GÊNESE TERRITORIAL A PARTIR DA ECONOMIA TRADICIONAL}

A análise da evolução socioeconômica de um lugar torna-se interessante à medida que um estudo como este proporciona a compreensão de sua formação e das transformações espaciais ocorridas ao longo dos processos. Estes proporcionam ao espaço mudanças; 
passando a ser entendido, portanto, como "uma realidade objetiva, um produto social em permanente transformação" (SANTOS, 2008a, p. 67). As atividades econômicas têm um papel primordial nessa transformação espacial. Sendo assim, vejamos como as atividades tradicionais, que foram destacadas em escala maior, contribuíram para o surgimento de Macaíba.

O Município localiza-se a $14 \mathrm{~km}$ da capital do Rio Grande do Norte, Natal, tem aproximadamente 70 mil habitantes e uma área bastante expressiva, cerca de $500 \mathrm{~km}^{2}$. (IBGE, 2010). Estando entre os dez municípios que compõe a Região Metropolitana de Natal. (figura 1).

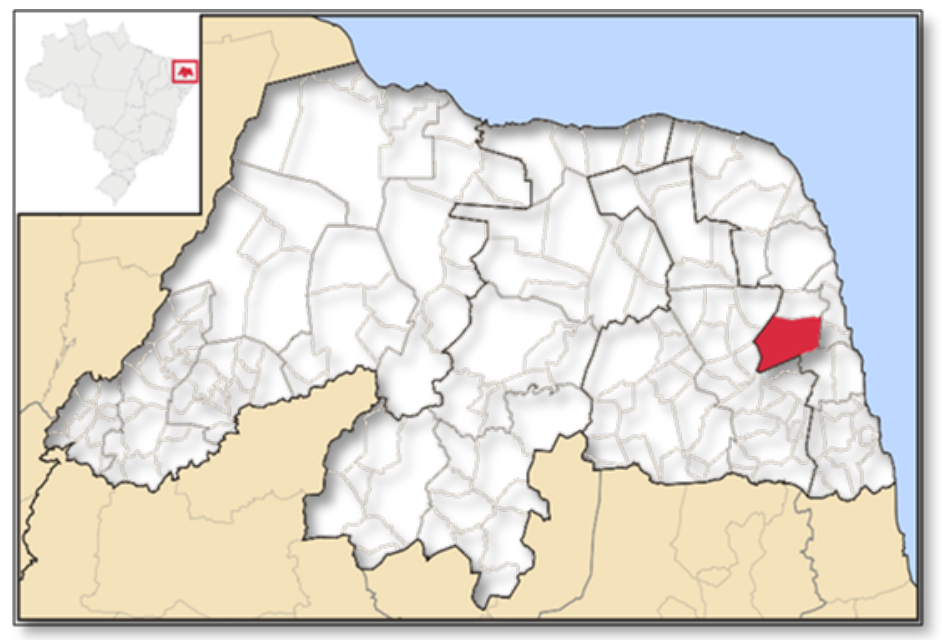

Figura 1: Em vermelho o municípios de Macaíba Fonte: www.RioGrandedoNorte_Municip_Macaiba.svg

Como se deu em uma escala maior, espaço norte-rio-grandense, a cidade tem os primeiros passos para sua ocupação a partir da atividade canavieira, isso ocorreu por causa da sua posição geográfica que se beneficia do Rio Jundiaí. Felipe (2010, p. 21) destaca que após a expulsão dos holandeses "[...] o Rio Grande do Norte retoma a produção de açúcar que conhece um momento de expansão, quando, em 1775, já registrava 27 engenhos e engenhocas espalhadas pelo litoral, próximos às várzeas terminais dos rios: Curimataú, Jundiaí, Potengi e Ceará-Mirim."

Próximo ao rio Jundiaí existia o engenho do Ferreiro Torto. Segundo Dantas (1985, p. 25) "[...] desde 1603, existiam os sítios Ferreiro Torto e Uruaçu, sendo que o primeiro, a partir de 1630, possuindo um engenho bangüê, que anualmente produzia cerca de cinqüenta mil quilos de açúcar. Ambos colhiam farinha de mandioca e milho, além de criar gado (...)". Atualmente é um patrimônio histórico de Macaíba (figura 2). 


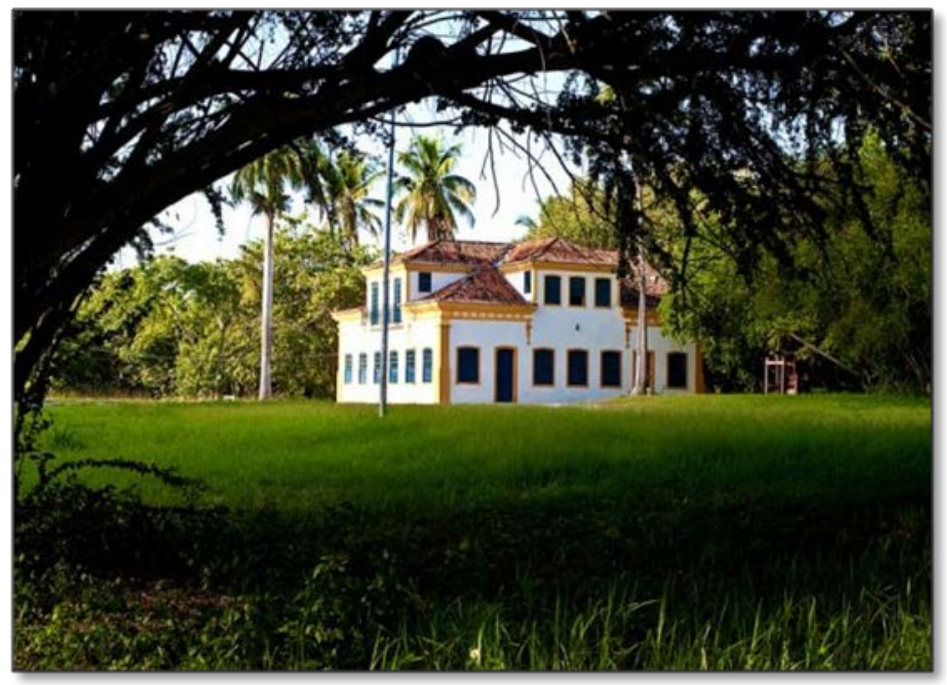

Figura 2: Solar Ferreiro Torto

Fonte: http://www.trampolimdavitoria.com

A criação de gado e a agricultura de subsistência eram uma realidade pertencente no primeiro momento nas proximidades dos engenhos. Nesse período, o povoado que na localidade se instalou dá início os primeiros passos para a produção do território e mesmo com o fim do cultivo da cana-de-açúcar em Macaíba, a cidade ainda participava das outras instâncias da produção como a comercialização e a circulação deste produto.

É necessário lembrar que, conforme Santos (2008b), só a produção tem a relação direta com o lugar e dele adquiri as condições necessárias para a sua realização. Assim, a importância que cada processo teve em cada momento e para cada caso particular ajuda a compreender a organização do espaço. Fazendo-nos entender que para apreender a organização espacial atual de Macaíba é necessário analisar os processos que contribuíram para sua formação.

Portanto, a atividade canavieira, que pelo litoral foi implantada, contribuiu para a instalação de equipamentos necessários a produção, a comercialização e a circulação do produto sobre o território. Em Macaíba os primeiros equipamentos a serem instalados foram o engenho Jundiaí e o armazém para estocar o produto para a sua comercialização. 0 engenho Foi instalado na fazenda de plantação e criação de gado cuja propriedade era de Francisco Bandeira tendo sido um dos primeiros equipamentos a ser construído (DANTAS, 1985). A importância da instalação desses equipamentos neste espaço se deu à medida que eles passam a representar em seu aspecto visível como uma forma geográfica, ou seja, representam frações do social, não sendo apenas formas, mas formas-conteúdos (SANTOS, 2008b).

A atividade canavieira entrou em decadência e, como já se sabe, a pecuária ganhou destaque na economia. Com a crescente demanda por carne-seca, solicitada por outros Estados, a uma expansão na criação de gado e o surgimento de oficinas de carne-seca. "Essa atividade espalhava-se por outras regiões do território potiguar, destacando-se a oficina de carne-seca, em Macaíba, às margens do Rio Jundiaí" (FELIPE, 2010, p. 22). Macaíba passou a ganhar novas formas-conteúdos, um passo a mais para a sua formação espacial. Além, de 
torna-se um local de apoio para os vaqueiros que traziam o gado do interior para o litoral do Estado.

A avaliação feita pelo autor em tela é que até o século XVIII a economia estadual resumia-se a produção de açúcar e a criação de gado, ao comércio que se realizava dos produtos derivados do gado (couros e peles) e ainda à produção de sal, mesmo que incipiente.

Entretanto, como já referido, a atividade algodoeira ganha espaço após o declínio da pecuária. E mais uma vez Macaíba participa da economia, não como um espaço, propriamente de produção do algodão, mas como um espaço de circulação e comercialização. Apesar de que, para Santos (2008b, p. 81) "[...] o processo direto de produção é, mais que outras instâncias produtivas (circulação, repartição, consumo), tributário de um pedaço de território." Mas, mesmo que o território de Macaíba não tenha sido tributário direto da produção do algodão, o seu surgimento como cidade propriamente dita se dá durante esta atividade.

Com efeito, Macaíba é beneficiada com o descaroçador de algodão, conforme Felipe et al (2006, p. 23) "[...] os descaroçadores pertenciam quase sempre a comerciantes instalados nas povoações e essas, por sua vez, se tornavam o ponto de convergência de produtores nos dias de feira, contribuindo para o seu desenvolvimento". Essa situação também se reflete em Macaíba. Já que, o descaroçador pertencia ao Senhor Fabrício Gomes Pedrosa, grande comerciante, que como relata Dantas $(1985$, p. 38):

Progredindo os seus negócios, logo instalou outra casa de comércio de tecidos e de secos e molhados. [...] motivando esse centro de atividades comerciais. A afluência de muitos interessados [...] viam para si também boas oportunidades de negócios e prosperidade na nascente povoação.

Esse quadro impulsionou ao pequeno povoado a se transformar em cidade. E assim, no final do século XIX, precisamente no dia 27 de outubro de 1877, através da Lei 801, a Vila de Coité foi elevada à categoria de Município, denominando-se Município de Macaíba.

É importânte que se considere que ao longo desses processos a cidade conheceu uma evolução socioeconomica e que entendê-la é essencial para a compreensão de como esses processos foram se geografizando ao longo do periodos. Conforme, Santos (2008b, p. 83b) "[...] o movimento dialético entre forma e conteúdo é igual ao movimento do todo social apreendido na realidade geográfica. As mudanças ocorrem de acordo com o período."

As economias tradicionais foram dessa forma de extrema importância para a produção do território potiguar e especificamente pode-se ver como elas se espacializaram no território macaibense, os equipamentos instalados e a contribuição do mesmo para a evolução socioeconômica do município proporcionaram uma organização do espaço adequando-o às necessidades de cada atividade.

Relações sociais foram estabelecidas e dinâmicas econômicas e políticas devolvidas, uma cultura gerada e um território constituído. Por isso, o espaço deve ser considerado como "[...] uma instância social, ao mesmo tempo em que as demais, ou seja, econômica, cultural- 
ideológica isso significa que o espaço como instância contém e é contido pelas demais." (SANTOS, 2008b, p. 11).

\section{AS ECONOMIAS MODERNAS NO ESTADO E (RE) PRODUÇÃO ESPACIAL}

As economias tradicionais entraram em crise e o Rio Grande do Norte passou a encontra alternativas econômicas em outras atividades tais como: a industrialização, fruticultura irrigada, produção de sal, turismo, mineração, o petróleo entre outras. Entretanto, essas atividades foram implantadas de forma gradativa, mas que mesmo de forma incipiente, mostraram-se como pontos de esperança para alavancar a economia potiguar.

De acordo com Felipe (2010) as primeiras reações do Estado para encontrar soluções para a crise instaurada pela falência das economias tradicionais foram: implantar um processo de industrialização, principalmente voltadas para o segmento têxtil. Esse processo obteve incentivos fiscais por meio da Superintendência de Desenvolvimento do Nordeste (SUDENE), criando o Polo Têxtil que atraiu muitas empresas para o Estado. A segunda reação, segundo o autor em tela, foi a implementação de programas habitacionais, que dinamizaram a produção de produtos (tijolos, cal, telhas e cimento) que subsidiam a construção civil. Essa ação ainda:

Promoveu a ampliação do setor terciário que veio por meio dos serviços de educação e saúde, que criam uma massa se salários com funcionários públicos, que geram as condições de consumo de serviços e mercadorias que refletem no crescimento do comércio. (FELIPE, 2010, p. 36).

O setor terciário ganha destaque e, sobretudo, o comércio impulsiona ainda mais um processo de urbanização. As cidades, nesse novo contexto, passam a ser o palco principal, pelo menos para maioria das atividades. Essa situação é um reflexo das ações externas e uma tendência a todos os países subdesenvolvidos, já que:

O papel do setor terciário é muito grande no processo geral de desenvolvimento e, em particular, no desenvolvimento urbano, em países subdesenvolvidos. Nas cidades pequenas ou nos embriões urbanos, no meio tradicional, a classe de funcionários constitui um dos raros exemplos desse terciário evoluído que, sem duvida nenhuma, tem um papel motor. Na vida urbana e regional, o terciário evoluído toma uma força social e econômica motora. (SANTOS, 2008a, p. 111).

Assim, no Rio Grande do Norte uma nova dinâmica espacial se estabelece, uma vez que, os territórios são reorganizados para atender as novas instâncias da produção. Para isso Ihe é acrescido infraestrutura que permita o fluxo de pessoas e mercadorias, e o aumento de serviços públicos. Sob essa perspectiva, Felipe $(2010$, p. 59) ressalta que "[...] as políticas publicas que criam estradas, o telefone internacional, o banco, os conjuntos habitacionais, as inovações que revitalizam a cidade reforçando o seu poder e sua capacidade de influência, geram funções de serviço [...]" que irá criar, por consequência, uma maior atração, principalmente da população da Zona Rural, pela cidade. 
No entanto, vale ressaltar que não se quer com isso, colocar o aumento do número de pessoas nas cidades como indicador de uma urbanização, mas apenas como um dado colaborador para a análise das transformações existentes, uma vez que, para Carlos (2007, p.105), "[...] as relações sociais se realizam concretamente enquanto relações espaciais, e, neste sentido, a análise do espaço aponta um processo de produção/reprodução da sociedade em sua totalidade." Sendo assim, deve-se ir bem mais além do que uma análise dos números da população e sim a partir das relações espaciais pela sociedade estabelecida. Além disso, o número da população urbana representa bem mais do que apenas uma concentração demográfica.

\begin{abstract}
Nesses termos, não se trata apenas de concentração demográfica, mas de concentração em si, e constituída de forma muito mais ampla, porque compreende o adensamento não apenas de pessoa, mas de obras, de objetos, de infra-estrutura, de equipamentos, de edificações, de acontecimentos, de idéias, de valores, de possibilidades etc. (SPOSITO 2006, p. 113).
\end{abstract}

Não nós deteremos a cada atividade, supracitadas especificamente, porque para o objetivo deste trabalho interessa-nos entender que a partir da crise das economias tradicionais, novas economias foram se instalando no Estado, outras se modernizaram, como a atividade salineira, e que adequaram o território as suas necessidades, gerando transformações espaciais importantes, como o processo de urbanização, tendo em vista a quantidade de pessoas que saíram da Zona Rural e foram para as cidades, principalmente a capital. Dessa forma, "[...] a concentração da população nas cidades gera novas contradições, transformando as cidades no locus do conflito social." (Felipe, 2010, p. 61).

Sendo assim, deve-se acrescentar que, em Macaíba, nem todas as atividades modernas, que se instalaram no Estado, contribuíram para o contínuo processo de (re) produção do espaço. Contudo, veremos como a cidade participa desse novo contexto em que se encontra o Rio Grande do Norte.

\title{
3.1 MACAÍBA: AS ECONOMIAS MODERNAS E AS MUDANÇAS ESPACIAIS
}

As consequências geradas com a decadência da economia tradicional também foram sentidas em nível local. Macaíba conheceu após seu período de expansão uma fase de "estagnação econômica". O seu período de expansão se deu necessariamente conforme Dantas (1985, p. 42) por:

Se situar entre os Rios Jundiaí e Potengi e as vizinhanças como vales do Cearamirim e do Mipibu, grandes produtores de açúcar, cereais e frutos, até as inúmeras condições que obrigavam, a outras áreas do interior, a só alcançarem a capital da província e posteriormente Estados, por seu intermédio, tornando-a, desse modo, entreposto obrigatório das mercadorias, que nas costas de animais vinham do Sertão para Natal [...] 
tudo isso como se pode avaliar, o que preponderantemente concorreu para o enriquecimento e a prosperidade de Macaíba.

O fim de seu período áureo vem com a retirada do porto de seu território e, atribui-se também, a criação das estradas de rodagem. Macaíba perde, dessa forma, o seu papel de entreposto comercial. Para Dantas $(1985$, p. 47) “[...] ironicamente fatores que em outras partes determinaram progresso e riqueza, como estrada de ferro e rodagem [...] para Macaíba foram determinantes do seu empobrecimento". Isso se deu porque "o sistema procura impor modernizações [...] os espaços atingidos são aqueles que respondem, em um dado momento, às necessidades de funcionamento ou crescimento do sistema." (SANTOS, 2008 b, p. 40). Por isso, nem todos os espaços são atingidos por modernizações da mesma forma colocando aqueles que as recebe em um patamar privilegiado.

Macaíba por um tempo não obteve grandes crescimentos economicamente e as atividades que no município eram praticadas restringiam-se a agricultura e ao setor terciário, representado por alguns funcionários públicos e pelo comércio, boa parte informal. Essa realidade começa a se esvaecer com a instalação de infraestrutura e equipamentos como (estradas, telefone, posto de saúde, rede escolar) que na década de 1970, para o município, representou um possível recomeço, pois impulsionou o comércio.

Assim, a cidade experimenta um processo de urbanização, impulsionado tanto pelo comércio quanto por pequenas fábricas que começam a se instalar em seu território. Outro fator relevante é a sua proximidade com a capital, participando assim, da região metropolitana ela passa a se beneficiar das modernizações implantadas nas regiões próximas.

E na década de 1990 é instalado o Centro Industrial Avançado (CIA) de Macaíba aprovado pela Lei 7.070 de 1997, que acarretou a vinda de muitas indústrias para o seu perímetro urbano. Essa atividade é grande consumidora do espaço urbano, contribuindo dessa forma, ainda mais para o crescimento do espaço urbano.

A população do município aumentou e com ela a construção civil, que tem estimulado o surgimento de condomínios tanto horizontais quanto verticais. Nem sempre acessível a todos, uma vez que, conforme Corrêa (1986, p. 29), o sistema capitalista atual torna a habitação um bem cujo acesso é seletivo. E, portanto, "parcela enorme da população não tem acesso, que dizer, não possui renda para pagar o aluguel de uma habitação decente, e muito menos, comprar um imóvel."

Outra atividade que tem se destacado é o comércio cujo fluxo pode ser observado nas (figuras 3 e 4), apesar de não ser uma prática recente no município, a forma como vem expandindo-se e reorganizado no espaço constitui-se em uma nova fase dessa atividade, apropriando-se de novos territórios e produzindo uma nova dinâmica, uma vez que novos serviços são oferecidos como: corretoras, serviços de saúde, serviços gráficos, de manutenção de equipamentos (computadores, impressoras entre outros), serviços antes apenas ofertados na capital. 


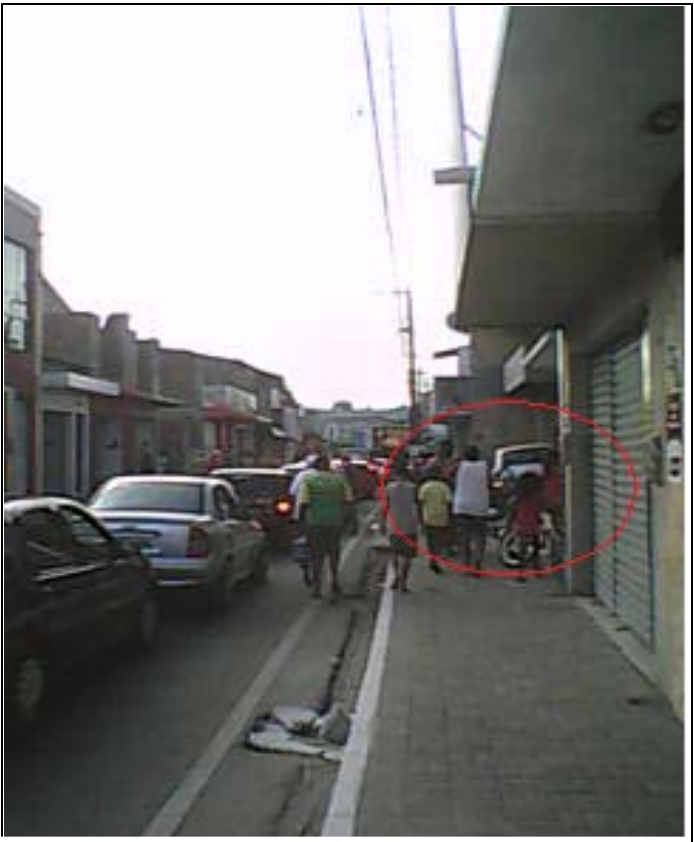

Figura 3: Carros e pessoas dividem ao mesmo tempo a calçada e a rua (destaque no circulo vermelho).

Fonte: A autora 2010

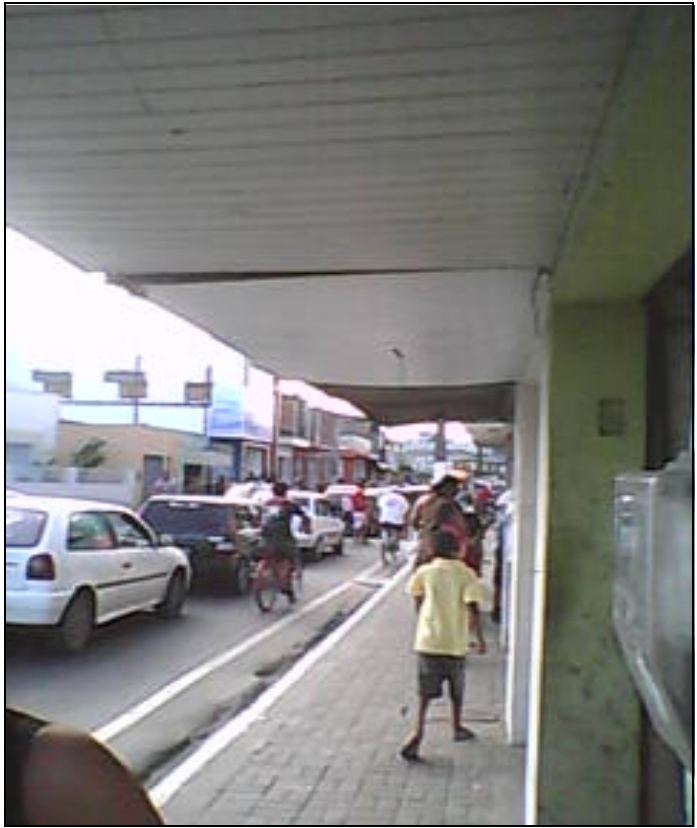

Figura 4: Comércio e transito na avenida professor Caetano em Macaíba. Fonte: A autora 2010

Como observado nas figuras 3 e 4, o crescimento do comércio não foi acompanhado por uma infrasestrutura adequada, as ruas são estreitas para o fluxo de pessoas e carros, não há locais para estacionamentos. Mas, apesar disto, é a atividade que mais gera renda e empregos, mesmo que informais, contribuindo de forma significativa para o Produto Interno Bruto (PIB) do município (gráfico 1).

\section{GRÁFICO 1 - PRODUTO INTERNO PRUTO (PIB) DE MACAÍBA, IBGE 2010}

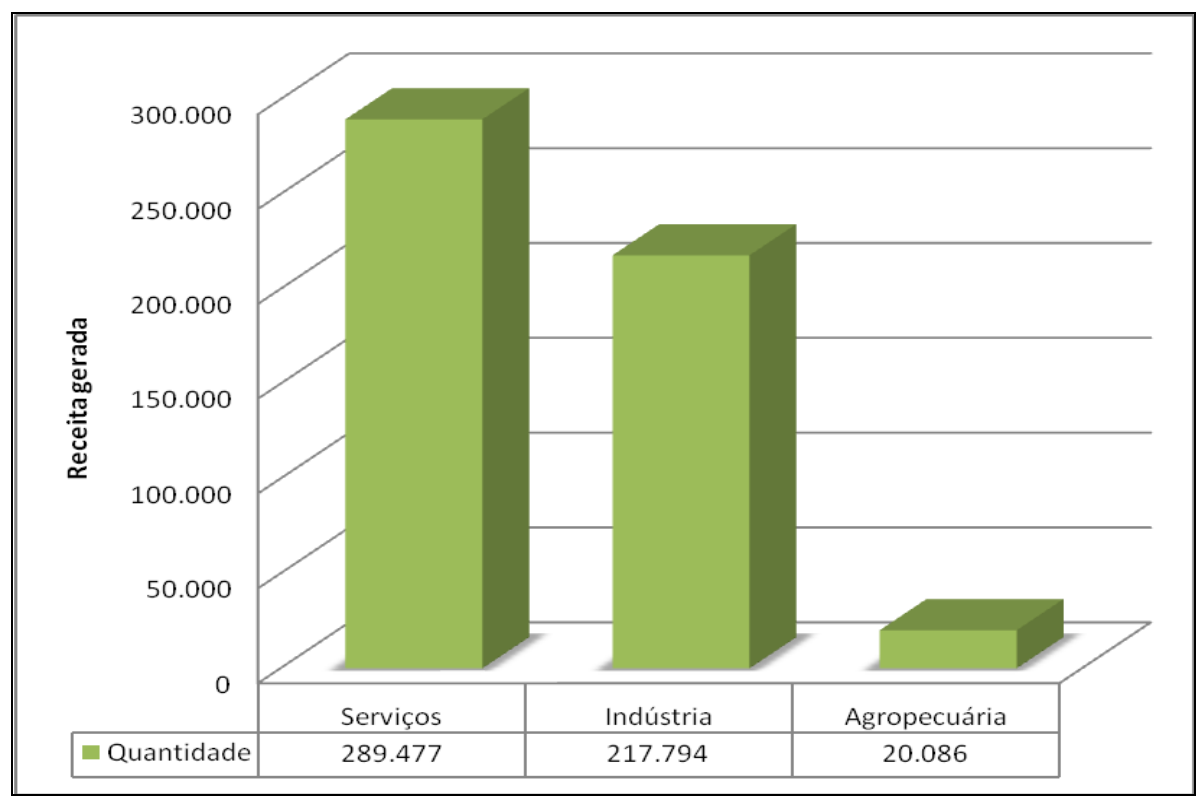


É importante ressaltar ao que se refere às indústrias, como pode ser observado, apesar de se constituir em um processo novo para o município tendo em vista que a sua formação socioespacial esteve atrelada ao comércio e a agricultura, essa atividade também tem contribuído significativamente para o PIB e para as mudanças espaciais, sobretudo, com a instalação de novos equipamentos e/ou melhoramentos dos já existentes para atenderem a necessidade de circulação das empresas, uma vez que, "[...] não basta produzir muito [...] é indispensável transformar as massa produzidas em fluxos." (SANTOS, 2008b, p. 83).

Diante desse contexto e, sob um olhar geográfico na economia potiguar, conforme Felipe (2010, p. 52) "[...] cabe uma prospectiva nos territórios projetados: o aeroporto de São Gonçalo do Amarante; as zonas de processamento de exportação de Açu e Macaíba." E precisamente sobre esta última, a nova ponte sobre o rio Jundiaí e a construção de um complexo rodoviário, que integrará todos os municípios da RMN, além de utilizará, para escoar sua produção, o novo aeroporto.

Dessa forma, torna-se perceptivel que Macaíba, por está iserida na RMN, acompanha uma tendência do Brasil, que são as especializações do território "[...] do ponto de vista da produção material, assim criadas, são raízes das complementaridades regionais [...] essas complementaridades fazem com que, em consequência, criem-se nescessidades de circulação[...]." (SANTOS, 2008a, p. 44). Sendo assim, será que não estaria havendo uma refuncinalização desse território cuja tendência é ser industrial.

Desse modo, pode-se perceber como a economia tem produzido territórios e como estes tem sido reproduzido ao longo dos processos. Macaíba em sua configuração espacial representa todos os processos sociais, ocorridos ao longo do tempo. Uma cidade que tem crecido consideravelmente, mas que infelizmente representa, também, um espaço de exclusão e de desorganização, principalmente do seu espaço urbano, uma vez que, o seu crescimento urbano ocorre de forma desordenada. Além disso, esse crescimento está calcado no setor secundário, alavancado pela formação de um pólo industrial, e terciário, parece negar o espaço rural calcado em uma agricultura atrasada, que pouco tem contribuído no sustento de boa parte dos seus habitantes.

\section{CONSIDERAÇÕES FINAIS}

Os elementos espaciais relacionam-se de maneira diferente em cada lugar, produzindo subespaços. Macaíba, assim, compartilhou do processo de formação territorial do Estado ao mesmo tempo em que o seu era formado, portanto, uma história dentro da história cujo palco principal é o seu território no qual o processo de produção foi tributário. Segundo Santos (2008b, p. 71) "a história é uma totalidade em movimento, um processo dinâmico cujas partes colidem continuamente para produzir cada novo momento."

O trabalho objetivou analisar a formação espacial de Macaíba a partir da economia tradicional e as mudanças ocasionadas pelas novas economias instaladas no município. No qual pode verificar que as atividades tradicionais assim como foram importantes para o processo de produção territorial do Estado foram para Macaíba, guardadas as proporções e as particularidades com que cada atividade utilizava as porções do território. Dessa forma, 
observou-se como a cada atividade da trilogia: cana-de-açúcar, pecuária e algodão, os territórios eram adequados na dialética economia e território.

Outro ponto, que foi privilegiado neste trabalho perpassa pela crise que as economias tradicionais sofreram e como os espaços foram afetados. Bem como, o surgimento de economias modernas. Na qual, se pode verificar que em Macaíba precisamente duas (Indústria e Comércio), entre as economias citadas, estão sendo responsáveis pela reprodução e um novo arranjo territorial, que promovem novas dinâmicas e novos processos espaciais, como a urbanização, uma vez que, neste novo período as atividades econômicas modernas, em Macaíba, voltam-se para o espaço urbano realizando o adensamento de pessoas equipamentos, infraestrutura e edificações no município.

Destarte, entender o processo de formação do território a partir das atividades econômicas tradicionais e a reprodução a partir das atividades modernas é essencial à medida que a análise proporciona a compreensão do lugar em sua totalidade a partir de eventos realizados em escala maior e como reflexo das ações do passado e das que são realizadas no presente.

\section{REFERÊNCIAS BIBLIOGRÁFICAS}

1. CARLOS, Ana Fani Alessandri. O Espaço Urbano: Novos Escritos sobre a Cidade. São Paulo: Labur Edições, 2007.

2. CORRÊA, Roberto Lobato. O Espaço urbano. Ed. São Paulo. Ática, 1986.

3. _. _. Trajetórias Geográficas. 2. Ed. Rio de Janeiro: Bertrand Brasil, 2001.

4. DANTAS, Meneval. Macaíba: Imagens, Sonhos, Reminiscências. 3. Ed. Natal/ Rio de Janeiro, Fundação José Augusto/ Presença Edições. 1985.

5. FELIPE, José Lacerda Alves. Rio Grande do Norte: uma leitura geográfica. Natal. RN: EDUFRN, 2010.

6. Et Al. Atlas do Rio Grande do Norte. Espaço Geo-Histórico e Cultural. Natal. Editora: Grafset. 2006.

7. GALVÃO. Maria Luiza de Medeiros. Geografia Rio Grande do Norte. Natal. Edição do autor, 2005.

8. GOMES, Rita de Cássia da Conceição. Fragmentação e gestão do território no Rio Grande do Norte. São Paulo: UNESP/Rio Claro. 1998. Tese de Doutorado - Programa de PósGraduação em Geografia, Universidade Estadual Paulista Júlio de Mesquita Filho, 1998.

9. SANTOS, Milton. Manual da Geografia Urbana. 3. Ed. São Paulo: Editora da Universidade de São Paulo, 2008a.

10. __ Espaço e Método. 5. Ed. São Paulo: Editora da Universidade de São Paulo, 2008b.

11. SPOSITO, Maria Encarnação Beltrão, WHITACKER, Arthur Magon. Cidade e campo: relações e contradições entre o urbano e rural. Ed. São Paulo: Expressão popular, 2006. 